\title{
An old dog learns new tricks: novel functions of the exocyst complex in polarized epithelia in animals Richard S Kang and Heike Fölsch*
}

Address: Department of Biochemistry, Molecular Biology \& Cell Biology, Northwestern University, 2205 Tech Drive, Evanston, IL 60208, USA

* Corresponding author: Heike Fölsch (h-folsch@northwestern.edu)

FI000 Biology Reports 2009, I:83 (doi: I0.34I0/BI-83)

The electronic version of this article is the complete one and can be found at: http://FI000.com/Reports/Biology/content///83

\begin{abstract}
The role of the exocyst complex has been studied mainly in the context of basolateral sorting of cargos in polarized cells. Recent developments indicate an extended yet specific function of the exocyst in the outgrowth of the primary cilium from the apical membrane, thereby highlighting a role for the exocyst in ensuring membrane trafficking to important signaling stations in the cell, the tight junctions, and the cilia.
\end{abstract}

\section{Introduction and context}

Cell polarity is maintained in part by targeted vesicular trafficking to the apical and basolateral membrane domains as well as the primary cilium of polarized cells. The cilium is a rod-like organelle featured on the apical plasma membrane domain on most epithelial cells in vertebrates, although the composition of the cilium membrane is not well understood. Increasing evidence indicates that polarized cell homeostasis is strongly affected by the 'health' of primary cilia, perhaps because cilia are needed for numerous cell signaling pathways such as polycystin, Wnt, and Hedgehog signaling $[1,2]$. Acute deciliation can result in the loss of polarity in cells, implying an important role for the cilium in maintaining cell polarity [3]. Furthermore, the loss of ciliary function is associated with cystic livers and kidneys as observed in Bardet-Biedl syndrome (BBS) and autosomal dominant polycystic kidney disease (ADPKD) [1].

The exocyst is a highly conserved complex with important roles in mediating targeted vesicular trafficking in polarized cells. The exocyst is an eight-subunit complex (Sec3, Sec5, Sec6, Sec8, Sec10, Sec15, Exo70, and Exo84) that was first identified as a requirement for exocytosis of vesicles at the bud tips of yeast [4]. In addition, the small GTPase Sec4 is essential for post-
Golgi trafficking in yeast [5], and the exocyst complex functions as an effector for Sec4 [6]. Biochemical evidence further indicates that yeast Sec3 interacts with the activated form of Cdc42 [7]. A current model of the exocyst delineates its function as a tethering complex in the trafficking of vesicles from a post-Golgi compartment, the recycling endosome, to the basolateral plasma membrane in columnar epithelial cells $[8,9]$. To accomplish this task, the exocyst associates with vesicles that contain the epithelial cell-specific clathrin adaptor complex AP-1B [10]. This process is regulated by the small GTPases Rab8, Rab10, Cdc42, and RalA [11,12]. Biochemical data indicate that both Sec5 and Exo84 interact with RalA in its GTP-bound form [13-16], and structural and biochemical work further reveals that Sec5 and Exo84 competitively bind to active RalA $[17,18]$, suggesting that RalA plays an important role in regulating exocyst assembly. These data established a role for the exocyst in basolateral sorting of cargo in polarized epithelial cells (Figure 1, arrow 1).

\section{Major recent advances}

Over the last couple of years, there has been mounting evidence that the exocyst also plays a role in vesicular trafficking to the cilium. Rogers et al. [19] were the first to show localization of the exocyst subunits Sec6/8 at the base of the primary cilium in addition to its known 
Figure I. Hypothetical model of the different roles of exocyst complexes in polarized epithelial cells

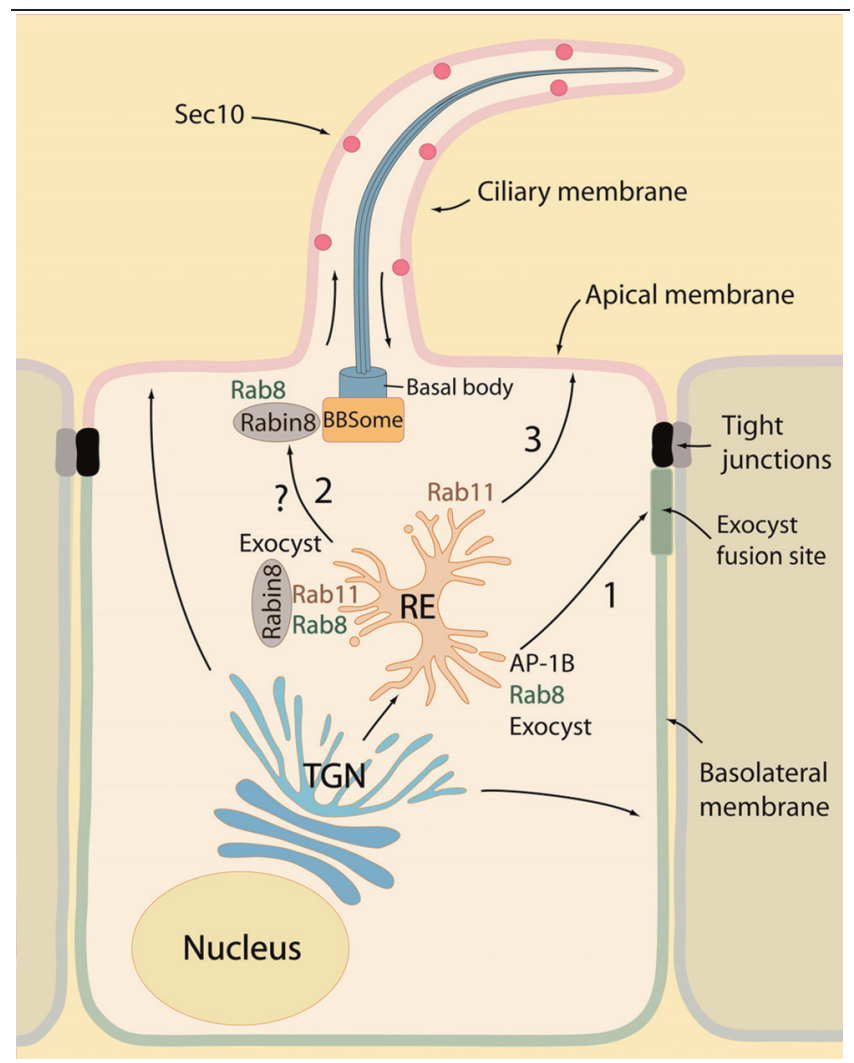

The sorting of biosynthetic cargos to different plasma membrane domains takes place either at the trans-Golgi network (TGN) or in recycling endosomes in polarized epithelial cells. Vesicular trafficking to the cilium may originate in recycling endosomes where Rab8 or Rabl I or both may regulate the organization of distinct subdomains. The exocyst has been shown to play a role in vesicular trafficking from the recycling endosomes (RE) to the basolateral membrane (arrow I) as well as in trafficking to the cilium in association with Rab8, Rabin8, and Rab I I (arrow 2). Vesicles may be directed to the base of the cilium by the interaction of Rabin8 and BBSI. RabII also has a known role in sorting to the apical membrane (arrow 3).

localization just below the tight junctions. They also demonstrated that Sec6/8 are overexpressed in ADPKD primary cell cultures and immortalized cell lines, suggesting a link between the ciliopathy ADPKD and the exocyst [19]. A recent study then demonstrated a direct role for the exocyst in primary ciliogenesis and cystogenesis in Madin-Darby canine kidney (MDCK) cells [20]. Knockdown of Sec10 in MDCK cells resulted in a decrease in cilium length which could be rescued with exogenous Sec10 expression [20]. In addition, knockdown of Sec10 resulted in decreased expression levels of Sec8 and Exo70, indicating that Sec10 may play a central role in exocyst organization at the cilium [20].
Moreover, knockdown of Sec10 decreased the levels of the intraflagellar transport protein 88 (IFT88), suggesting that trafficking of IFT88 to cilia may be exocystdependent [20]. In the future, it will be interesting to learn whether similar findings will be observed with genetic mutations of Sec10 or other exocyst components.

Notably, the exocyst is not the only component with a dual function in targeting to the basolateral membrane and cilia. Rab8a, which was described as a GTPase involved mainly in regulating cargo sorting to the basolateral membrane [21], was recently shown to localize to the primary cilium membrane in human retinal pigmented epithelial cells and to function in primary cilium formation [22]. Similarly, in cilia-derived sensory organelles, the rod outer segments, Rab8 plays a role in docking and fusion of rhodopsin transport carriers (RTCs) [23], and Rab8 co-localizes with Sec8 in the vicinity of RTC fusion sites in Rana berlandieri frog cells [24]. Interestingly, the Rab8 guanine nucleotide exchange factor Rabin8 interacts directly with the BBS1 subunit of a multimeric complex, the BBSome, that localizes at the base of the cilium and regulates ciliary membrane biogenesis [25]. It is Rabin8 that provides a link between Rab8 and the exocyst complex. Biochemical data indicate that Rabin8 may interact with Sec15 and GTP-loaded Rab11 (Wei Guo, personal communication). Furthermore, Rab11 has been shown to bind to the C-terminus of Sec15 [26-28], indicating a cooperative action between the exocyst and Rab8 and Rab11 GTPases in regulating vesicular trafficking to the primary cilium (Figure 1, arrow 2).

The role of the exocyst in sorting to cilia or cilia-derived structures seems to be conserved from invertebrates to vertebrates, although the majority of epithelial cells in invertebrates do not contain cilia. However, Drosophila photoreceptor cells have a light-sensing microtubule structure on their apical stalk membrane. Sorting of rhodopsin 1 to rhabdomeres and rhabdomere formation are also dependent on Sec6, Sec15, and Rab11 function $[27,29]$, highlighting the importance of the exocyst in cilia formation.

\section{Future directions}

Models describing vesicular trafficking into the cilia are sparse in the literature. However, this should soon change with the identification of players involved in this pathway. In the effort to establish a model, certain questions become apparent. For example, it is intriguing to note that the exocyst and Rab8 are used for both cilium outgrowth and sorting to the basolateral membrane, whereas Rab11 plays a role in cilium biogenesis in 
addition to its known function in regulating apical delivery of the polymeric IgA receptor as it transcytoses from the basolateral to the apical membrane (Figure 1, arrow 3) [26]. How are these different pathways delineated? Given the known localization of Rab8, Rab11, and the exocyst in different areas of recycling endosomes $[10,21,26,30]$, it seems conceivable to assume that the pathway to the cilium involving these components may be originating in recycling endosomes. Perhaps the recycling endosomes are organized in three subdomains, each regulating a specific trafficking step and thereby preventing missorting of apical or basolateral cargos into the cilium. Indeed, the organization of recycling endosomes into apical and basolateral domains is so dramatic that they are often referred to as 'apical recycling endosomes' and 'central recycling endosomes' (for a detailed discussion of this topic, see [31]). Perhaps Rab8 and Rab11 are involved in forming such subdomains. Future studies will be necessary to analyze whether this is indeed the case. Another unknown is where vesicles that are targeted to the cilia fuse with the ciliary membrane. Perhaps they are directed first to the base of the cilium via the interaction between Rabin 8 and BBS1. From the base of the cilium, vesicles may be directed into the cilium on microtubule tracks because Sec10 stains the entire length of the cilia membrane [20], implying that fusion of vesicles takes place along the ciliary membrane; however, it is not clear whether such fusion might occur as there is currently no evidence for the presence of transport vesicles in cilia. Alternatively, fusion of vesicles may occur at the base of the cilium, thereby leading to the outgrowth of ciliary membrane. As researchers continue to make strides toward understanding the role of the exocyst in polarized epithelial cells, mechanisms of how one complex may specifically regulate multiple membrane trafficking steps will be unraveled.

\section{Abbreviations}

ADPKD, autosomal dominant polycystic kidney disease; BBS, Bardet-Biedl syndrome; IFT88, intraflagellar transport protein 88; MDCK, Madin-Darby canine kidney; RTC, rhodopsin transport carrier.

\section{Competing interests}

The authors declare that they have no competing interests.

\section{Acknowledgements}

We thank Wei Guo (University of Pennsylvania, Philadelphia, PA, USA) for sharing unpublished data. The authors are supported by National Institutes of Health grants GM070736 (to HF) and T32 GM08061 (to RSK).

\section{References}

I. Gerdes JM, Davis EE, Katsanis N: The vertebrate primary cilium in development, homeostasis, and disease. Cell 2009, 137:32-45.

2. Low SH, Vasanth S, Larson CH, Mukherjee S, Sharma N, Kinter MT, Kane ME, Obara T, Weimbs T: Polycystin-I, STAT6, and PI00 function in a pathway that transduces ciliary mechanosensation and is activated in polycystic kidney disease. Dev Cell 2006, 10:57-69.

3. Overgaard CE, Sanzone KM, Spiczka KS, Sheff DR, Sandra A, Yeaman C: Deciliation is associated with dramatic remodeling of epithelial cell junctions and surface domains. Mol Biol Cell 2009, 20:102-13.

4. TerBush DR, Maurice T, Roth D, Novick P: The Exocyst is a multiprotein complex required for exocytosis in Saccharomyces cerevisiae. Embo J 1996, I 5:6483-94.

5. Salminen A, Novick PJ: A ras-like protein is required for a postGolgi event in yeast secretion. Cell 1987, 49:527-38.

6. Guo W, Roth D, Walch-Solimena C, Novick P: The exocyst is an effector for Sec4p, targeting secretory vesicles to sites of exocytosis. Embo J 1999, I 8:1071-80.

7. Zhang X, Bi E, Novick P, Du L, Kozminski KG, Lipschutz JH, Guo W: Cdc42 interacts with the exocyst and regulates polarized secretion. J Biol Chem 200I, 276:46745-50.

FI000 Factor 6.0 Must Read

Evaluated by Anthony Bretscher 05 Nov 2001

8. Grindstaff KK, Yeaman C, Anandasabapathy N, Hsu SC, RodriguezBoulan E, Scheller RH, Nelson WJ: Sec6/8 complex is recruited to cell-cell contacts and specifies transport vesicle delivery to the basal-lateral membrane in epithelial cells. Cell 1998, 93:731-40.

9. Yeaman C, Grindstaff KK, Wright JR, Nelson WJ: Sec6/8 complexes on trans-Golgi network and plasma membrane regulate late stages of exocytosis in mammalian cells. J Cell Biol 200I, I 55:593-604.

10. Fölsch H, Pypaert M, Maday S, Pelletier L, Mellman I: The AP-IA and AP-IB clathrin adaptor complexes define biochemically and functionally distinct membrane domains. J Cell Biol 2003, | 63:35|-62.

II. Fölsch $\mathrm{H}$ : The building blocks for basolateral vesicles in polarized epithelial cells. Trends Cell Biol 2005, I5:222-8.

12. Schuck S, Gerl MJ, Ang A, Manninen A, Keller P, Mellman I, Simons K: Rab 10 is involved in basolateral transport in polarized MadinDarby canine kidney cells. Traffic 2007, 8:47-60.

FI000 Factor 3.0 Recommended Evaluated by Keith Mostov 10 May 2007

13. Brymora A, Valova VA, Larsen MR, Roufogalis BD, Robinson PJ: The brain exocyst complex interacts with RalA in a GTP. dependent manner: identification of a novel mammalian Sec3 gene and a second Secl5 gene. J Biol Chem 200I, 276:29792-7

14. Moskalenko S, Henry DO, Rosse C, Mirey G, Camonis JH, White MA: The exocyst is a Ral effector complex. Nat Cell Biol 2002, 4:66-72.

FI000 Factor 6.4 Must Read

Evaluated by Michel Labouesse 08 Jan 2002, Keith Mostov 28 Jan 2002

15. Moskalenko S, Tong C, Rosse C, Mirey G, Formstecher E, Daviet L, Camonis ], White MA: Ral GTPases regulate exocyst assembly through dual subunit interactions. J Biol Chem 2003, 278:5 I743-8.

16. Sugihara K, Asano S, Tanaka K, Iwamatsu A, Okawa K, Ohta Y: The exocyst complex binds the small GTPase RalA to mediate filopodia formation. Nat Cell Biol 2002, 4:73-8.

17. Fukai S, Matern HT, Jagath JR, Scheller RH, Brunger AT: Structural basis of the interaction between RalA and Sec5, a subunit of the sec6/8 complex. Embo J 2003, 22:3267-78. 
18. Jin R, Junutula JR, Matern HT, Ervin KE, Scheller RH, Brunger AT: Exo84 and Sec5 are competitive regulatory Sec6/8 effectors to the RalA GTPase. Embo J 2005, 24:2064-74.

19. Rogers KK, Wilson PD, Snyder RW, Zhang X, Guo W, Burrow CR, Lipschutz $\mathrm{JH}$ : The exocyst localizes to the primary cilium in MDCK cells. Biochem Biophys Res Commun 2004, 319:138-43.

20. Zuo X, Guo W, Lipschutz JH: The exocyst protein SeclO is necessary for primary ciliogenesis and cystogenesis in vitro. Mol Biol Cell 2009, 20:2522-9.

FI000 Factor 3.0 Recommended Evaluated by Heike Folsch 24 April 2009

21. Ang AL, Fölsch H, Koivisto UM, Pypaert M, Mellman I: The Rab8 GTPase selectively regulates AP-IB-dependent basolateral transport in polarized Madin-Darby canine kidney cells. J Cell Biol 2003, 163:339-50.

22. Yoshimura SI, Egerer J, Fuchs E, Haas AK, Barr FA: Functional dissection of Rab GTPases involved in primary cilium formation. J Cell Biol 2007, I78:363-9.

FI000 Factor 3.0 Recommended

Evaluated by James Briscoe 2I Aug 2007

23. Moritz OL, Tam BM, Hurd LL, Peranen J, Deretic D, Papermaster DS: Mutant rab8 Impairs docking and fusion of rhodopsin-bearing post-Golgi membranes and causes cell death of transgenic Xenopus rods. Mol Biol Cell 200I, I2:234I-5I.

24. Mazelova J, Ransom N, Astuto-Gribble L, Wilson MC, Deretic D: Syntaxin 3 and SNAP-25 pairing, regulated by omega-3 docosahexaenoic acid, controls the delivery of rhodopsin for the biogenesis of cilia-derived sensory organelles, the rod outer segments. J Cell Sci 2009, I 22:2003-13.
25. Nachury MV, Loktev AV, Zhang Q, Westlake CJ, Peränen J, Merdes A, Slusarski DC, Scheller RH, Bazan JF, Sheffield VC, Jackson PK: A core complex of BBS proteins cooperates with the GTPase Rab8 to promote ciliary membrane biogenesis. Cell 2007, 129:1201-13.

FI000 Factor 6.5 Must Read

Evaluated by Keith Mostov 20 Jun 2007, Robert Parton 21 Jun 2007, Robert S Krauss 03 Jul 2007

26. Oztan A, Silvis M, Weisz OA, Bradbury NA, Hsu SC, Goldenring JR, Yeaman C, Apodaca G: Exocyst requirement for endocytic traffic directed toward the apical and basolateral poles of polarized MDCK cells. Mol Biol Cell 2007, I 8:3978-92.

27. Wu S, Mehta SQ, Pichaud F, Bellen HJ, Quiocho FA: Secl 5 interacts with Rab I I via a novel domain and affects Rab I I localization in vivo. Nat Struct Mol Biol 2005, 12:879-85.

28. Zhang XM, Ellis $S$, Sriratana A, Mitchell CA, Rowe T: Secl5 is an effector for the Rab I I GTPase in mammalian cells. J Biol Chem 2004, 279:43027-34.

29. Beronja S, Laprise P, Papoulas O, Pellikka M, Sisson J, Tepass U: Essential function of Drosophila Sec6 in apical exocytosis of epithelial photoreceptor cells. J Cell Biol 2005, 169:635-46.

FI000 Factor 6.0 Must Read

Evaluated by Michel Labouesse II Nov 2005

30. Prigent M, Dubois T, Raposo G, Derrien V, Tenza D, Rosse C, Camonis J, Chavrier P: ARF6 controls post-endocytic recycling through its downstream exocyst complex effector. J Cell Biol 2003, 163:|||||-2|.

31. Fölsch $\mathrm{H}$ : Regulation of membrane trafficking in polarized epithelial cells. Curr Opin Cell Biol 2008, 20:208-13. 